\title{
Oral Hygiene Routine of Functionally Dependent Elderly Individuals Performed by Home Caregivers
}

Cariles Silva de Oliveira', Maria Sueli Marques Soares ${ }^{2}$, Selene Cordeiro Vasconcelos ${ }^{3}$, Carmem Sílvia Laureano Dalle Piagge ${ }^{4}$, Ângela Maria Klüppel da Silva ${ }^{5}$, Aimée Guimarães Cabral6, Adriana Maria Moreira Alexandre Barreto", Ana Giovana Medeiros de Oliveira ${ }^{8}$, Ana Zuli Vidal Moreira de Freitas ${ }^{9}$, Antonia Oliveira Silva ${ }^{10}$

\section{Abstract}

Introduction: The rapid ageing of the population in Brazil has been accompanied by an increase in chronic and debilitating diseases. Thus, elderly individuals often require the participation of a caregiver in the home. Caregivers are responsible for the oral hygiene of functionally dependent individuals, which, when performed improperly, is associated with local and general health problems that can exacerbate underlying systemic conditions and exert a negative impact on quality of life.

Objective: The aim of the present study was to investigate the oral hygiene routine of functionally dependent elderly individuals executed by home caregivers.

Method: An exploratory, descriptive, cross-sectional study with a quantitative approach was conducted involving 20 caregivers of functionally dependent elderly individuals in the city of João Pessoa, Brazil. The elderly individuals took part in an interdisciplinary homecare program offered through public healthcare system that did not include dental care. Semi-structured interviews were held involving the administration of a questionnaire addressing issues related to the oral hygiene of the patients, such as denture maintenance, the use of hygiene materials and the difficulties the caregivers face when performing oral care.

Results: Thirty-five percent of the caregivers only had an elementary school education, 35\% had a high school education, $25 \%$ had a uni-
1 Dentist and Nurse. Specialist in Gerontology. Member of the International Research Group on Aging and Social Representations, UFPB, Brazil.

2 Dentist. PhD in Stomatology. Professor of Dentistry, UFPB, Brazil.

3 Nurse. PhD in Neuropsychiatry and Behavioral Sciences. Professor of Nursing, UFPB, Brazil.

4 Dentist. PhD in Dental Prosthetics. Professor of Dentistry, UFPB, Brazil.

5 Dentist. Member of the International Research Group on Aging and Social Representations, UFPB, Brazil.

6 Graduate Student of the Dentistry, UFPB, Brazil.

7 Social Worker. Member of the International Research Group on Aging and Social Representations, UFPB, Brazil.

8 Dentist. Student of Postgraduate Course in Gerontology, UFPB, Brazil.

9 Dentist. Member of the International Research Group on Aging and Social Representations, UFPB, Brazil.

10 Nurse. PhD in Nursing. President of the Institute on Aging, UFPB, Brazil.

\section{Contact information:}

Selene Cordeiro Vasconcelos.

” selumares@gmail.com 
versity education and 5\% were illiterate; $80 \%$ had not received any information on oral hygiene care for functionally dependent elderly individuals; $55 \%$ were related to the patient and 45\% were formal caregivers. Moreover, $55 \%$ of the caregivers reported difficulties performing oral health care for the elderly individuals. The use of an ordinary toothbrush and toothpaste was reported by $35 \%$ of the caregivers; these resources plus mouthwash were reported by $20 \%$ and $20 \%$ reported the use of mouthwash and other resources, such as gauze, cotton, diaper and a fingertip toothbrush. None of the caregivers reported using dental floss or a tongue cleaner and $60 \%$ did not remove the individual's dentures at night.

Conclusion: The caregivers interviewed demonstrated inadequate knowledge regarding the proper oral hygiene routine for functionally dependent elderly individuals. Moreover, care was based on empirical knowledge and guidance from the family. Thus, the inclusion of a dentist to the interdisciplinary team of the homecare program is recommended for the proper monitoring of oral health practices for elderly individuals and for carrying out educational activities for caregivers with the aim of improving the oral hygiene routine. It is believed that this study can contribute to the avoidance of local and systemic complications, thereby improving the quality of life of functionally dependent elderly individuals.

\section{Keywords}

Home Nursing; Oral Hygiene; Frail Elderly, Caregivers.

\section{Introduction}

As has occurred in other developing countries, the rapid, progressive increase in the elderly population in Brazil has led to a clear demographic transition that needs to be addressed adequately [1, 2]. Thus, governmental policies have been established to ensure care for the elderly, such as the Statute of the Elderly (Law 10.741/2003) and the National Policy for Elderly Health $[3,4]$.

The main problem identified in this population is the loss of functional capacity, which regards the physical and mental abilities necessary to execute basic and instrumental activities of daily living [5]. Moreover, the number of very elderly individuals has also grown and such individuals have specific health needs, including oral health care [6]

A homecare program was established by the Brazilian public healthcare system involving teams of doctors, nurses and nursing assistants who offer care for a particular period of time and train caregivers to provide continued care [7]. However, there is a need to include other health specialists, such as dentists. Moreover, the different contexts of elderly care require interdisciplinary and multidisciplinary approaches based on specific needs to ensure the prevention and detection of health problems [8].

Home caregivers are primarily responsible for the health of elderly individuals and constitute the link 
between the family and multidisciplinary team. Caregivers should stimulate self-care, empowerment and autonomy based on the functional capacity of the elderly patient and take over the full responsibility of care when necessary [2]. Oral hygiene is one of the basic activities of self-care and, when performed improperly, is related to the occurrence of local and systemic diseases, with the consequent deterioration of general health and a reduction in quality of life [9]. However, caregivers can experience difficulties in managing the oral hygiene of elderly individuals due to the prioritization of other types of health care that are considered more complex. This situation is associated with a lack of knowledge and skill, which further hinder adequate oral hygiene, especially when the patient offers resistance [10].

The aim of the present study was to investigate the oral hygiene routine of functionally dependent elderly individuals performed by home caregivers. The knowledge generated by this study is hoped to enable improvements in the training of caregivers regarding the performance of this important task.

\section{Method}

An exploratory, descriptive, cross-sectional study with a quantitative approach [11] was conducted at the homes of elderly individuals enrolled in the interdisciplinary homecare program offered by the public healthcare system in the city of João Pessoa, Brazil. This program does not offer oral care.

The sample of caregivers was obtained based on the records of elderly individuals in the homecare program $(n=30)$. Twenty caregivers assisted functionally dependent individuals and composed the population of the present study. Despite the small sample size, the results could be generalized to situations with similar characteristics regarding functionally dependent elderly individuals, the difficulties caregivers face and the absence of a dentist on multidisciplinary homecare teams.
The inclusion criteria were male or female adults who provided direct, continuous care for functionally dependent elderly individuals enrolled in the homecare program. Caregivers with cognitive impairment or other medical condition that made it difficult to understand the questionnaire were excluded.

Data collection was conducted through semistructured interviews of the caregivers administered by a single researcher. The questionnaire addressed the oral hygiene routine, denture care, the use of materials and the difficulties the caregivers faced in performing oral care.

A descriptive analysis of the variables studied was conducted with the aid of the Statistical Package for the Social Sciences (SPSS, version 23.0).

This study received approval from the Human Research Ethics Committee of Health Sciences Center under process number 566/06 in compliance with the regulating norms governing research involving human subjects stipulated in Resolution 466/2012 of the Brazilian National Health Council. The participants were given clarifications regarding the objectives and were assured confidentiality and anonymity [12]. All participants signed a statement of informed consent.

\section{Results}

All caregivers were female. Mean age was 50 years, but $20 \%$ were older than 60 years of age and three of these caregivers had chronic diseases. Most caregivers (80\%) had no technical training in healthcare. Only four caregivers had training: one nurse, one speech therapist and two nursing technicians

\section{(Table 1)}

All caregivers considered oral hygiene very important. The criteria used to perform the oral hygiene routine focused on empirical knowledge from the personal routine of the caregiver $(n=$ $12 ; 60 \%)$, orientation from speech therapists (n $=4 ; 20 \%$ ) and guidance from the patient's family 
Table 1. Profile of caregivers of functionally dependent elderly individuals.

\begin{tabular}{|l|c|c|}
\hline \multicolumn{1}{|c|}{ Variable } & N & $\%$ \\
\hline Age Group & & \\
\hline 20 to 30 years & 1 & 5 \\
\hline 31 to 40 years & 4 & 20 \\
\hline 41 to 50 years & 5 & 25 \\
\hline 51 to 60 years & 6 & 30 \\
\hline 61 to 70 years & 2 & 10 \\
\hline Sex & & \\
\hline Male & 0 & 0 \\
\hline Female & 20 & 100 \\
\hline Level of Education & & \\
\hline Illiterate & 1 & 5 \\
\hline Elementary School & 7 & 35 \\
\hline High School & 7 & 35 \\
\hline Higher Level Education & 5 & 25 \\
\hline Relationship to Elderly Individual & & \\
\hline Formal Caregiver with Health Training & 2 & 10 \\
\hline Formal Caregiver without Health Training & 7 & 35 \\
\hline Relative without Health Training & 9 & 45 \\
\hline Relative with Health Training & 2 & 10 \\
\hline
\end{tabular}

$(n=2 ; 10 \%)$. Ten percent $(n=2)$ reported more than one source of knowledge. Regarding the time required to complete the procedure, $50 \%(n=10)$ of the caregivers reported 1 to 5 minutes, 30\% $(n=6)$ reported 5 to 10 minutes, $5 \%(n=1)$ reported more than 10 minutes and 15\% ( $n=3)$ reported that the time varied. Seventy percent ( $\mathrm{n}$ $=14$ ) of the respondents reported performing the oral hygiene of the elderly individuals more than once a day, $25 \%(n=5)$ reported performing the task once a day and $5 \%(n=1)$ had not adopted any systematic frequency.

The most common material used for oral hygiene was toothpaste ( $n=15 ; 75 \%$ ), followed by a common toothbrush $(n=13 ; 65 \%)$ and mouthwash ( $n$ $=11 ; 55 \%$ ), with no report of the use of adapted or electric toothbrushes or tongue cleaners. Nine respondents (45\%) reported other unconventional resources, such as gauze, cotton, diaper and a fingertip toothbrush. The main combination of material resources was a common toothbrush and toothpas- te ( $n=7 ; 35 \%$ ), followed by toothbrush, toothpaste and mouthwash ( $n=4 ; 20 \%)$, mouthwash and other material resources ( $n=4 ; 20 \%$ ), toothpaste and other material resources $(n=1 ; 5 \%)$ and toothpaste, mouthwash and other material resources $(n=1 ; 5 \%)$. Moreover, $10 \%(n=2)$ made use of more than three materials. Eighty percent $(n=$ 16) caregivers reported performing hygiene of the tongue, but none used a tongue cleaner; $50 \%$ ( $n=$ 8) used common a toothbrush, 43.8\% ( $n=7)$ used toothpaste, $62.5 \%(n=10)$ used mouthwash and $56.2 \%(n=9)$ used other resources.

Only $25 \%(n=5)$ of caregivers assisted elderly who wore dentures; $20 \%(n=1)$ performed cleaning and disinfection once a day and $80 \%$ ( $n=$ 4) performed these procedures more than once a day. Denture cleaning was performed mainly after meals ( $n=4 ; 80 \%)$, but $20 \%(n=1)$ had no systematized time. A common toothbrush $(n=4$; $80 \%$ ), stiff bristle brush for dentures ( $n=1 ; 20 \%$ ) and toothpaste ( $n=5 ; 100 \%)$ were the material resources employed. No use of auxiliary resources was mentioned. Sixty percent $(n=3)$ of the caregivers did not remove the prosthesis at night. Among those who removed the prosthesis $(n=2$; $40 \%$ ), half stored the dentures in recipients with water and half stored the dentures in recipients with mouthwash diluted in water.

In the total sample of caregivers, $55 \%(n=11)$ reported difficulties in the implementation of the oral hygiene routine. Among this subsample of caregivers, $72.7 \%(n=8)$ reported more than one type of difficulty, $81.8 \%(n=9)$ reported limited access to the oral cavity, $72.7 \%(n=8)$ reported that the elderly individuals were unable to assist in the execution of the procedure and $63.6 \%(n=$ 7) reported that the elderly individuals refused to submit themselves to the procedures. The majority of caregivers ( $n=13 ; 65 \%$ ) had no standardized method for the implementation of the oral hygiene routine. 


\section{Discussion}

The investigation of the oral hygiene routine of functionally dependent elderly individuals performed by home caregivers enabled the identification of the difficulties caregivers face with regard to executing this procedures as well as a lack of knowledge on the systemic consequences of inadequate oral hygiene. The practices were mainly guided by the caregiver's empirical knowledge and/or orientation provided by family members. A lack of preparation for the management of functionally dependent elderly individuals as well as a lack of skills regarding the use of material resources and the systematization of the oral hygiene routine were the main findings of the present study.

Poor oral hygiene in elderly individuals has been related to nutritional problems and systemic conditions, such as cardiovascular disease and respiratory infection. Moreover, it is a cause of tooth decay and coated tongue and is associated with increases in hospitalization rates and healthcare costs, thereby compromising quality of life [9]. Thus, the oral hygiene routine for functionally dependent elderly individuals requires certain skills on the part of the caregiver [13].

Care in such cases is generally provided by family members, mostly women, which strengthens the role of the family as the primary source of social support and informal care [14-17]. In the present study, the predominance of female caregivers, aged 51 to 60 years old with a low level of education is in agreement with data described in previous studies $[17,18]$.

Over the decades, changes have been seen in this scenario of care, as caregivers of the elderly have become an integral part of the cultural aspect of exercising home care as a means of earning an income. However, the actions of the public and private sectors with regard to the support and qualification of caregivers remain limited [14, 15].

The dissonant behavior exhibited by the caregivers with regard to considering oral hygiene to be important and failures in the execution of this routine care was also identified previous studies $[19,20]$. Such behavior was evidenced by the inadequate hygiene time, frequency and use of auxiliary materials as well as the problems reported in managing functionally dependent elderly individuals, such as difficulty gaining access to the oral cavity and a lack of cooperation on the part of the patient [10].

Treating coated tongue by proper cleaning is part of oral hygiene care and is essential to maintaining systemic health, particularly with regard to the prevention of respiratory infections. However, this aspect of oral care was overlooked by the caregivers, which is in agreement with the deficient tongue hygiene found in a previous study [21]. Likewise, shortcomings in the cleaning of a dental prosthesis, which is considered a potent biofilm reservoir, can lead to injuries to the surrounding mucosa, with harmful effects on the remaining teeth [21]. Therefore, caregivers of the elderly should be aware of appropriate care methods and cleaning materials for dentures and abutments [10].

The use of additional resources and techniques as well as the systematization of procedures can facilitate oral care, especially for less cooperative patients, making oral hygiene practice safer for the elderly patient as well as less tiring and stressful for the caregiver [9].

Considering the peculiarities and characteristics of health promotion for functionally dependent elderly individuals, poor oral health is a source of concern for geriatric dentists, as it has been associated with infection and the development of diseases with systemic repercussions [9]. Due to a lack of knowledge and skills, caregivers do not understand the harmful consequences of poor oral hygiene to the health of elderly individuals [22]. Thus, in addition to adequate training, a continuing education program in oral health for caregivers is very important to meeting the specific demands of the geriatric public $[13,14$, $22,23]$. Challenges regarding the oral hygiene rou- 
tine are related to the health conditions of the elderly, the caregivers themselves and the underlying socio-cultural context. To meet these challenges, actions that include all people involved in the care of the elderly are recommended, along with specific public policies and intersectoral collaboration for the promotion of oral health in this portion of the population [15].

The present study demonstrates the need to include the investigation of the oral hygiene routine of functionally dependent elderly individuals in the planning of integral health care for this population. Moreover, the findings are in agreement with data described in a previous study that identified a failure among caregivers to include an adequate oral hygiene routine as part of their daily tasks [24, 25].

\section{Conclusion}

The present study investigated the oral hygiene routine of functionally dependent elderly individuals performed by home caregivers. The caregivers organized the care routine primarily based on their own knowledge and/or guidance provided by the family. However, a lack of technical and scientific knowledge regarding the performance of these procedures and the use of material resources was identified, along with difficulties in the management and systematization of the oral hygiene routine. Moreover, the caregivers did not demonstrated adequate understanding of the relationship between poor oral hygiene and the harmful systemic consequences for functionally dependent elderly individuals.

\section{Recommendations}

The present findings underscore the need to include a dentist in the interdisciplinary homecare team to monitor the oral health care of elderly individuals, perform direct clinical interventions and ensure the permanent education of the caregivers responsible for the oral hygiene routine. Expert support would enable actions based on the specific needs of each elderly individual, with the avoidance or minimization of local or systemic diseases stemming from inadequate oral hygiene.

\section{References}

1. Dawalibi NW, Anacleto GMC, Witter C, Goulart RMM, Aquino RC. Envelhecimento e qualidade de vida: análise da produção científica da SciELO. Estud psicol. 2013; 30(3):393-403.

2. Floriano LA, Azevedo RCS, Reiners AAO, Sudré MRS. Cuidado realizado pelo cuidador familiar ao idoso dependente, em domicílio, no contexto da estratégia de saúde da família. Texto Contexto Enferm. 2012; 21(3):543-8.

3. Brasil. Lei federal $n^{\circ} 10.741$, de 01 de outubro de 2003. Estatuto do idoso. Brasília, DF: Secretaria Especial dos Direitos Humanos. 2004

4. Ministério da saúde (Brasil). Política Nacional de Saúde da Pessoa Idosa. Portaria No 2.528, de 19 de outubro de 2006. Brasília (DF). 2006.

5. Ministério da Previdência Social (Brasil). Estudos: Envelhecimento e Dependência: Desafios para a Organização da Proteção Social. Brasília. 2008; 28:160.

6. Azenha MR, Handem RH, Lacerda SA, Bueno EG. Estudo epidemiológico da saúde bucal da população idosa. IJD. Int J Dent. 2011; 10(4):228-33.

7. Ministério da Saúde (Brasil). Internação Domiciliar no âmbito do SUS. Portaria n 2.529 de 19 de Outubro de 2006. Institui a Internação Domiciliar no âmbito do SUS. Brasília (DF). 2006.

8. Arnaldo SM, Abreu LC, Oliveira AYM, Delfino JAS, Matias ACX, Silva MA, et al. Analysis of the Action Strategies of the Brazilian National Health Policy of the Elderly from the Perspective of Nurses. Int Arc Med. 2016; 9(71):1-11.

9. Kuo YM, Yen M, Fetzer S, Chiang LC, Shyu YI, Lee TH, et al. A home-based training programme improves family caregivers' oral care practices with stroke survivors: a randomized controlled trial. Int J Dent Hygiene. 2016; 14:82-91

10. Zellmer M, Gahnberg L, Ramberg P. Prevalence of halitosis in elderly living in nursing homes. Int J Dent Hygiene. 2016; 14(4):295-300.

11. Estrela, C. Metodologia científica: ensino e pesquisa odontológica. 2. ed. São Paulo: Artes Médicas; 2005.

12. Conselho Nacional de Saúde (Brasil). Resolução $n^{\circ} 466$, de 12 de dezembro de 2012. Aprova normas regulamentadoras de pesquisas envolvendo seres humanos. Brasília: Diário Oficial da União; 2013.

13. Lewis A, Wallace J, Deutsch A, King P. Improving the oral health of frail and functionally dependent eldery. Austr Dent J. 2015; 60 suppl 1:S 95-105. 
14. Yu SDF. Effects of a Health and Social Collaborative Case ManagementModel on Health Outcomes of Family Caregivers of Frail Older Adults: Preliminary Data from a Pilot Randomized Controlled Trial. J Amer Geriatr Society. 2016; 64(10):2144-8.

15. Smith MB, Thomson WM. 'Not on the radar': dentists' perspectives on the oral health care of dependent older people. Gerodontol. 2016; 1-11.

16. Almeida TL. Características dos cuidadores de idosos dependentes no contexto da Saúde da Família. Rev Bras Med Famil Comunid. 2006; 2(6):149.

17. Uesugui HM; Fagundes DS, Pinho DLM. Perfil e grau de dependência de idosos e sobrecarga de seus cuidadores. Act Paul Enferm. 2011; 24(5):689-94.

18. Conceição LFS. Saúde do Idoso: orientações ao cuidador do idoso acamado. Rev Med MG. 2010; 20(1):81-91.

19. Morishita S, Watanabe Y, Ohara Y, Edahiro A, Sato E, Suga T, et al. Factors associated with older adults need for oral hygiene management by dental professionals. Geriatrics Gerontol Int. 2016; 16:956-62.

20. Almeida LGCB, Costa PAM, Monteiro CSPD, Lima EMCX. Avaliação do conhecimento dos cuidadores sobre a higiene bucal de pacientes idosos institucionalizados. Int J Dentist. 2011; 10(3):137-42.

21. Seo H-Y, Jeon J-E, Chung $\mathrm{W}-\mathrm{G}, \mathrm{Kim} \mathrm{N}-\mathrm{H}$. Activities of daily living and oral hygiene status of older Korean patients in a long-term care facility. Int J Dent Hygiene. 2016:1-7
22. Prayoonwong $T$, Wiwatkhunupakan $T$, Lasuka $D$, Srisilapanan $P$. Oral Health Care Situation of Dependent Older People: Older Health Care Stakeholders' Perspectives. Gerontol Geriatr Res. 2015; 4(9):1-5.

23. Lee JH, Hwang TY. Oral health status and care needs of elderly patients in long-term care hospital. J Korean Soc Dent Hygiene. 2015; 15(3):411-6

24. Gaszynska E, Szatko F , Godala M, Gaszynski T. Oral health status dental treatment needs and barriers to dental care of elderly care home residents in Lodz, Poland. Clin Interv Aging. 2014; 9:1637-44.

25. Reigle JA, Holm K. Knowledge of oral health of nursing staff caring for disadvantaged older people. J Nurs Educ and Practice. 2016; 6:31-8.
Publish in International Archives of Medicine

International Archives of Medicine is an open access journal publishing articles encompassing all aspects of medical science and clinical practice. IAM is considered a megajournal with independent sections on all areas of medicine. IAM is a really international journal with authors and board members from all around the world. The journal is widely indexed and classified Q2 in category Medicine. 